R. de Roche $\cdot$ U. Rauchfleisch $\cdot$ B. Noelpp •

V. Dittmann • A. Ermer • R. D. Stieglitz · J. J. Staub •

Ch. Meier - T. C. Gasser • N. J. Lüscher

\title{
A team approach to the indication for gender reassignment surgery in transsexuals resulting in long-term outcome improvement
}

Received: 19 November 2003 / Accepted: 18 December 2003 / Published online: 12 March 2004

(C) Springer-Verlag 2004

\begin{abstract}
At the University of Basel (Switzerland), a multidisciplinary team was established for pre-operative selection and treatment of patients with gender dysphoria. As a result, the indications for surgical gender reassignment could be judged with considerably greater accuracy than previously possible. In the 9-year period of this prospective study only 14 of 57 patients with gender dysphoria were selected for surgical treatment. At the time of this survey, six patients are still under psychiatric preoperative evaluation, and six further male-to-female transsexuals are under hormonal treatment awaiting surgery. Following the operation, only one of nine male-tofemale patients is socially unstable and that patient's quality of life is worse than prior to gender reassignment. Of the female-to-male transsexuals, all four are stable in their professional and family relations. In conclusion, a comprehensive evaluation of patients with gender dysphoria and the conclusive indications established within
\end{abstract}

R. de Roche $(\square) \cdot$ N. J. Lüscher Department of Reconstructive Plastic Surgery,

University Hospital, Basel, Switzerland

e-mail: roland.de.roche@mis-bs.ch

Tel.: +41-61-3033070, Fax: +41-61-3033071

U. Rauchfleisch · V. Dittmann · A. Ermer

Department of Forensic Psychiatry,

University Hospital, Basel, Switzerland

B. Noelpp · J. J. Staub · C. Meier

Department of Endocrinology,

University Hospital, Basel, Switzerland

R. D. Stieglitz

Psychiatric Outpatient Department,

University Hospital, Basel, Switzerland

T. C. Gasser

Urology Department, University Hospital,

Basel, Switzerland

R. de Roche

Coordinator of the Transsexuals Interdisciplinary Treatment Team, Basel University, Clinic at Merian Iselin Hospital,

Thannerstrasse 80, 4054 Basel, Switzerland the team considerably improved the postoperative outcome of gender reassignment.

Keywords Transsexualism - Preoperative selection . Surgical gender reassignment - Prospective long-term follow up

\section{Introduction}

Surgical gender reassignment is considered to be the therapy of choice in the diagnosis of genuine transsexuality. The path of the transsexual to the desired goal of surgical gender reassignment accompanied by a legal change of identity is one involving an extended chain of visits to administrative and medical facilities. This is accompanied by an increasing sense of need that frequently evolves into panic induced by fear of failing the psychiatric assessment. As a result, the patient seeks a physician receptive to his demands and one that responds quickly under the frequently applied pressure of suicidal threats or self-inflicted harm. This leads to an expedient assessment and ensuing surgical treatment. The combined forces of overwhelmed relatives and general practitioners, psychiatrists with limited experience in the specific problems facing transsexuals, as well as uncritical and biased self-help groups, together with the frequently sensational reports in the press unduly influence the progress of therapeutic measures for gender reassignment. Inevitably the involved specialists are played off one against another. Following a chaotic decision process, the surgical team ultimately finds itself in the passive role of an executive body, which has not been consulted about the indication for operation but, nonetheless, is required to carry out surgery.

\section{Patients and methods}

Following negative feedback from operated transsexuals which included difficulty in coping with everyday life, being unable to work and ensuing social disintegration, and in one case the 
manifestation of schizophrenia [7], procedures were changed at the Basel University Clinic. On the initiative of the plastic surgeons, an interdisciplinary team for the evaluation and care of transsexuals was founded at the University Clinic in 1993. This group consists of psychiatrists, psychologists, endocrinologists, urologists and plastic surgeons who meet every 2 months to exchange detailed information on the course of treatment of each patient. Gynaecologists and voice specialists are consulted as required. Irrespective of which specialist the patient initially approaches, he will only be treated at Basel University if he agrees to be under the care of the whole team and explicitly consents to the mutual exchange of information within the working group. This inhibits the almost regular practice of playing off one team member against another, and enables the establishment of clearly structured treatment procedures.

Our diagnostic concept and the therapeutic procedure corresponds largely with the recommendations for interdisciplinary evaluation of transsexuals in Germany and Austria [6], these are based on the principles of the Harry Benjamin Gender Dysphoria Association, and consist of the following steps: (1) A minimum 1year treatment span of psychotherapy with a psychiatrist or psychologist of the patient's choice. (2) A psychiatric-psychological assessment by a member of our working group. (3) Following the expertise and an initial endocrinological and surgical consultation, the patient is called for an interview by the team. Hereafter the decision is made for or against surgical gender reassignment. In cases of doubt an additional 6 to 12 months of psychiatric/ psychological treatment is prescribed, followed by further team discussions. (4) If the recommendation by the team is positive, opposing gender hormone therapy is initiated which is simultaneously accompanied by a suitability test for everyday life involving cross-dressing for at least 1 year. (5) Thereafter a further brief assessment by the team psychiatrist or psychologist. (6) This is followed by a joint re-evaluation of the entire preparation phase as well as all assessments. Ideally the conclusion is a definitive indication for surgical reassignment. (7) Gender reassignment surgery. (8) Therapy with psychotherapists or psychologists continues after the operations to facilitate integration into society in the new sex role.
Between 1993 and December 2001, 63 subjectively transsexual patients were discussed, advised and when necessary, treated by the interdisciplinary team. There were only 14 cases (of 57 completed evaluations), which were operated on during this period. At this point in time a further six patients are still under preoperative psychiatric evaluation. A definitive surgical indication for gender reassignment has not yet been established by the team. The following is a presentation of detailed results taken from the complete reports made by the interdisciplinary team.

\section{Results}

Of 53 male-to-female transsexuals, the indication for surgical gender reassignment was established in only nine cases. On average the first legally implicit operation was carried out 25.6 months following the initial introduction of a patient at a team meeting. This invariably consisted of castration, penectomy and the formation of a vagina by inverting the external skin of the penis, as well as the construction of a clitoris using a neurovascular flap from the glans. At the second stage, in all patients trimming and Z-plasty of the labia was performed some months later. Postoperative check-ups after an average of 58.0 months $(8-102)$ showed that eight of the nine 'new women' were socially well-integrated and satisfied with the results of the operation (Table 1). All eight obtained new, in some cases better, positions in their previous professions. One of these is a self-employed businesswoman in customer relations who is currently unemployed due to an idiopathic facial palsy. One patient has only just established herself in her new role after 5 years

Table 1 Postoperative course of nine male-to-female transsexual patients

\begin{tabular}{|c|c|c|c|c|c|}
\hline $\begin{array}{l}\text { Patient/age at } \\
\text { first operation }\end{array}$ & $\begin{array}{l}\text { Follow-up } \\
\text { (months) }\end{array}$ & $\begin{array}{l}\text { Subjective } \\
\text { outcome }\end{array}$ & Sexual relationship & Profession & $\begin{array}{l}\text { Additional surgery (months after } \\
\text { gender reassignment) }\end{array}$ \\
\hline 1: 26 & 102 & $\begin{array}{l}\text { Distinctly } \\
\text { improved }\end{array}$ & Inconstant & $\begin{array}{l}\text { Same profession with } \\
\text { public contact, self- } \\
\text { employed; currently not } \\
\text { working due to illness }\end{array}$ & $\begin{array}{l}5 \text { months: vaginal widening flap } \\
17 \text { months: labioplasty, urethroplasty }\end{array}$ \\
\hline 2: 43 & 80 & $\begin{array}{l}\text { Distinctly } \\
\text { improved }\end{array}$ & Married & $\begin{array}{l}\text { New job with public } \\
\text { contact }\end{array}$ & $\begin{array}{l}6 \text { months: labioplasty } \\
23 \text { months: urethroplasty } \\
55 \text { months: rhinoplasty }\end{array}$ \\
\hline 3: 48 & 89 & Worse & None & $\begin{array}{l}\text { Unemployed, disability } \\
\text { pension }\end{array}$ & $\begin{array}{l}6 \text { months: labioplasty } \\
28 \text { months: breast augmentation }\end{array}$ \\
\hline 4: 43 & 76 & $\begin{array}{l}\text { Distinctly } \\
\text { improved }\end{array}$ & $\begin{array}{l}\text { Looking for a } \\
\text { male partner, } \\
\text { living together } \\
\text { with her } \\
\text { divorced wife }\end{array}$ & $\begin{array}{l}\text { Same company, } \\
\text { promotion, additional } \\
\text { public position }\end{array}$ & 5 months: labioplasty \\
\hline 5: 41 & 53 & Improved & $\begin{array}{l}\text { Inconstant, } \\
\text { preferably } \\
\text { women }\end{array}$ & $\begin{array}{l}\text { New job, computer } \\
\text { branch in public } \\
\text { institution }\end{array}$ & $\begin{array}{l}\text { Immediate revision (bleeding) } \\
4 \text { months: vaginal widening flap } \\
10 \text { months: breast augmentation } \\
17 \text { months: labioplasty } \\
23 \text { months: revision vaginal stump }\end{array}$ \\
\hline $6: 34$ & 58 & Improved & $\begin{array}{l}\text { Constant female } \\
\text { partner }\end{array}$ & $\begin{array}{l}\text { Initially casual work, } \\
\text { alcoholism; now } \\
\text { studying psychology }\end{array}$ & $\begin{array}{l}1 \text { month: skin graft for vaginal } \\
\text { defect } \\
9 \text { months: labioplasty, breast } \\
\text { augmentation }\end{array}$ \\
\hline 7: 31 & 37 & Improved & $\begin{array}{l}\text { Constant male } \\
\text { partner }\end{array}$ & $\begin{array}{l}\text { Self-employed in her } \\
\text { old profession }\end{array}$ & $\begin{array}{l}9 \text { months: labioplasty } \\
23 \text { months: vaginal widening flap }\end{array}$ \\
\hline 8: 53 & 19 & Improved & Female partner & Same job & 10 months: labioplasty \\
\hline 9: 40 & 8 & Improved & None & Same job & 7 months: labioplasty \\
\hline
\end{tabular}


Table 2 Postoperative course of four female-to-male transsexual patients

\begin{tabular}{|c|c|c|c|c|c|}
\hline $\begin{array}{l}\text { Patient/age at } \\
\text { first operation }\end{array}$ & $\begin{array}{l}\text { Follow-up } \\
\text { (months) }\end{array}$ & Subjective outcome & $\begin{array}{l}\text { Sexual } \\
\text { relationship }\end{array}$ & Profession & $\begin{array}{l}\text { Additional surgery (months after } \\
\text { gender reassignment) }\end{array}$ \\
\hline 10: 29 & 43 & Distinctly improved & Married & Same job, promotion & 13 months: scar correction breast \\
\hline 11: 22 & 32 & Distinctly improved & Married & $\begin{array}{l}\text { Graduate from high- } \\
\text { school, employed in } \\
\text { new profession }\end{array}$ & None \\
\hline 12: 43 & 29 & Improved & None & Same job & $\begin{array}{l}11 \text { months: preforming forearm flap } \\
13 \text { months: colpectomy }+ \text { micro- } \\
\text { vascular phalloplasty } \\
16 \text { months: scar corrections breast }+ \\
\text { phallus } \\
19 \text { months: revision urethral fistula } \\
25 \text { months: permanent urethral fistula } \\
28 \text { months: testicular implants }\end{array}$ \\
\hline 13: 24 & 12 & Distinctly improved & $\begin{array}{l}\text { Same female } \\
\text { partner }\end{array}$ & $\begin{array}{l}\text { Promotion in same } \\
\text { company; undergoing } \\
\text { further training abroad }\end{array}$ & None \\
\hline
\end{tabular}

of temporary jobs in geriatric and psychiatric nursing, followed by treatment for her considerable alcohol problem, and she is now studying psychology. One "new woman' has married and four others have stable partnerships. One of these, although interested in men, is still living with her ex-wife. Four out of nine patients, by their own account, have sex regularly with men, two have no sexual relationships at the moment and three admit to preferring lesbian relationships. Among these is a 'new woman' who sustained a partial necrosis and contracture of the neovagina. Only one woman experienced a drop in her social status: she became unable to work at her old job as a bricklayer due to osteoporosis, an already existing disc protrusion, and morbid obesity. As a result she had to exchange her previous above-average income for a disability pension. She was one of the two patients whose pronounced masculine disposition inhibited her ability (in a purely somatic sense) to convincingly transform into the female role. Nonetheless, in the team's view this single argument against surgical gender reassignment in a context of general suitability was not sufficient reason for rejection in the case of either patient.

Of the 32 male-to-female transsexuals who were not operated on by our team, five did not pass our strictly structured preparation phase, and opted alternatively for premature operations, in some cases at their own expense, at other centres. In the case of two of these patients, there were clear psychiatric contraindications to gender reassignment. We have no information regarding further developments in these cases. Six further patients explicitly broke off contact with our team (as a rule, due to the allegedly slow progress of our investigations) while eight just stopped attending without notifying the team. Ten were ultimately excluded from an operation due to psychiatric contraindications. Two further patients were excluded from the prerequisite oestrogen medication as one manifested AIDS, and the other had pre-existing atrial fibrillation with a recurring pulmonary embolism. Finally, one male-to-female patient was an asylum seeker from a family of devout Muslims, which resulted in reservations as to the indication for cross-gender therapy until it was documented that he was in possession of a residence permit, thus inhibiting an involuntary return to his culture of origin.

Additionally there are currently 12 male-to-female patients who are candidates for gender reassignment. Six transsexuals are undergoing psychiatric evaluation. For the other six, the indication for sex change treatment has been established and they are currently in the phase of cross-dressing in public and receiving hormone therapy.

Of nine female-to-male patients, four had a hysterectomy, oophorectomy and mastectomy (Table 2) on average 26 months following the initial introduction to the interdisciplinary team. Three 'new men', two of whom made the decision following some hesitation, decided against a phalloplasty. It was apparent that stable partnerships and satisfying sexual experiences contributed significantly to that decision. In any case this factor subjectively outweighed the prospect of an extensive and complex operation with no guarantee of penetration capability as well as the possible risk of damage to the nerves of the hypertrophic clitoral penoid resulting in decreased sensitivity. Only one new man who was single at the time opted for phallus construction using a radial forearm free flap. All cases in the female-to-male group involved clear indications for gender reassignment and did not encompass borderline situations or serious doubts. Of the five patients who were excluded all exhibited clear evidence of schizoid personality disorders.

Finally, we treated one patient for 'passing transsexualism' and the effects of gender reassignment carried out at age 20. In this male-to-female transsexual, we established the indication for renewed partial surgical reassignment to the male sex and removed the breast implants. A period of nearly 20 years and long-term psychiatric therapy separated the two gender reassignment operations. We were also able to obtain a new legal status for the patient who has meanwhile married. 


\section{Discussion}

The classical literature on the catamnesis of transsexuals who have opted for surgery regularly confirms the statistical observation that following gender reassignment, a third of transsexuals live happier postoperative lives, a third feel equally unsatisfied after achieving the ultimate goal of the longed-for operation, and a third have clearly deteriorated socially in comparison to their pre-surgery status. The common weakness of all such studies is the fact that there are invariably only a fraction of patients available for the catamnesis. As a result a statistical selection occurs, and it can only be speculated as to whether it was mainly the well-integrated patients, or rather those who were socially uprooted who ignored follow-up examinations. A recent study of our own patients in the past [4] emphasized this dismal conclusion. Of 69 transsexual patients who underwent surgery between 1970 and 1990, of an average of 14 years postop, only 17 could be assessed. There was a serious deterioration in the social situation and well being of the 13 male-to-female transsexuals: nine live on a disability pension or social security and are considerably isolated socially, three regretted the gender reassignment, of which two underwent operations in an attempt to re-acquire their original genetic gender. Two of the four female-to-male patients were employed and established in long-term partnerships, the remaining two suffered from depression and addictive behaviour. Of a population of 218 transsexuals in Gothenburg (between 1972 and 1992) only eight patients regretted the gender reassignment operation up to a period of 24 years postop, representing only $4 \%$ total of the gender reassignment patients [2].

Our negative experiences led us to rethink the criteria for initiating gender reassignment surgery and to share the responsibility for the decision among an interdisciplinary team of specialists who collectively resolve and supervise each step of the evaluation and treatment. As a team we were more effectively able to resist pressure from patients and to carry out a structured treatment procedure. Equally we were in a better position to inhibit the playing off of the various specialists one against another and to evaluate the complete group of patients for prospective long-term follow up.

In the first 9 years of our extremely time-demanding work only 14 of 57 patients who completed the evaluation actually underwent surgery, six are in the preoperative suitability test at the time being. In six further cases the evaluation is as yet not complete. Only one of the 14 patients who underwent surgery has a poorer quality of life than previous to surgery.

The initial experience in our interdisciplinary work strengthened our view that it is vital to adhere precisely to the indication criteria to ensure a successful long-term outcome. A comprehensive psychiatric and somatic evaluation is an absolute prerequisite for the ensuing plan of therapy. The study of our own cases [7] produced the following results: 9 out of 18 patients underwent a genetic examination and two with Klinefelter syndrome were di- agnosed. The next step involves consideration of the emotional stability and resilience of the patient as well as his susceptibility to psychosis or other psychiatric disturbances. We found that the postoperative prognosis was primarily dependent on social and occupational integration. Two other cases of male-to-female transsexuals made it clear that regardless of a positive psychiatric evaluation, an extremely masculine appearance should be a criterion for exclusion from gender reassignment as the patient has little insight into his visual effect in public. Obesity, in combination with increasing age, seems to be an additional risk factor and a relative contraindication for gender reassignment. The three youngest 'new women' of our patient group kept their slim feminine figure following the operation; four of the older patients put on a minor amount of weight following the initiation of oestrogen therapy, whereas the two eldest put on more than 15 kilograms during the observation period of 4 years and 1 year, respectively. These criteria will be given more attention in our team decisions in the future. In one of the largest evaluated groups of operated transsexuals in Stockholm [1], 90 out of 136 patients were assessed after an average of 5.8 years, and they revealed the same pattern of relevant characteristics, which are crucial for a prognosis. Personal and social instability, an unrealistic body image and surgery past the age of 30 correlate with unsatisfactory progress. In contrast, strong family support, stable partnerships and a profession which can be continued after gender reassignment are factors which facilitate integration into the new role. In another Swedish study [3] additional negative factors significant in the prognosis of male-to-female transsexuals were identified as completed military service and typically male occupations.

We find it particularly important to keep the patients in psychotherapy postoperatively so that in an unavoidable crisis situation the patient will not be inhibited in seeking psychiatric treatment. A study carried out in the USA [5] indicated the significance of long-term postoperative psychological care of the patients, their families and partners. This is regardless of a high level of patient satisfaction in terms of their professional, social and personal circumstances, as well as in terms of cosmetic appearance or genital orgasm capabilities.

We are convinced that our caution in considering a surgical indication meets current qualitative standards; intervention is cost-intensive and by no means risk-free. Thus it should be reserved for those transsexuals who indicate a high level of probability of adapting to and successfully re-socializing within the new gender role. This restrictive approach can only be carried out by a team which is committed to meeting high ethical standards, which functions well together and which can resist the demands of the transsexual consistently and fairly. In our opinion, the large amount of gender reassignment operations which occur for example in Germany and the Netherlands, as well as the higher frequency of operations carried out at the University of Basel previous to the establishment of our interdisciplinary team, documents an 
undue liberal attitude in a period of increasing public discussion on the taboo topic of transsexuality. Congruently a lack of long-term postoperative checks has inhibited transparency on the high rate of negative postoperative developments.

\section{Conclusion}

An individual therapist is often unable to resist the pressure coming from the patient and is compelled to recommend hormone therapy and surgery for the unprepared transsexual. General practitioners and endocrinologists in particular are inclined to submit without a clearcut diagnosis and regardless of the instable psychological condition of the patient. This is particularly the case of patients having initiated self-therapy with medication acquired from the black market. If hormone therapy is prescribed by a doctor, the patient interprets this action as a first step towards gender reassignment and it is seen as an almost irreversible admission of the patient's condition. However the psychiatric diagnosis is inhibited by hormone therapy, which causes a change in the patient's libido and psychological state. Accommodating the patient in other ways in order to allay him/her or simply to get respite from her/his demands, is counter-productive. In the complex treatment and counselling of transsexuals it is imperative for the successful long-term outcome that the classical sequence is precisely adhered to. This should consist of diagnosis, psychiatric long-term treatment, definitive diagnosis by a neutral expert, and ultimately endocrinological and experienced surgical therapy as well as psychological and socio-psychiatric follow-up care.

\section{References}

1. Eldh J, Berg A, Gustafsson M (1997) Long-term follow up after sex reassignment surgery. Scand J Plast Reconstr Hand Surg 31:39-45

2. Landen M, Walinder J, Hambert G, Lundström B (1998) Factors predictive of regret in sex reassignment. Acta Psychiatr Scand 97:284-289

3. Lindemalm G, Körlin D, Uddenberg N (1987) Prognostic factors versus outcome in male-to-female transsexualism. A follow-up study of 13 cases. Acta Psychiatr Scand 75:268-274

4. Rauchfleisch U, Barth D, Battegay R (1998) Resultate einer Langzeitkatamnese von Transsexuellen. Nervenarzt 69:799_ 805

5. Rehmann J, Lazer S, Benet AE, Schaefer LC, Melman A (1999) The reported sex and surgery satisfactions of 28 postoperative male-to-female transsexual patients. Arch Sex Behav 28:71-89

6. Sohn M, Peek A (1999) Grenzen der operativen Geschlechtstransformation bei Transsexualität. Acta Chir Austriaca 31: 248-254

7. Wyler J, Battegay R, Krupp S, Rist M, Rauchfleisch U (1979) Der Transsexualismus und dessen Therapie. Schweiz Arch Neurol Neurochir Psychiat 124:43-58

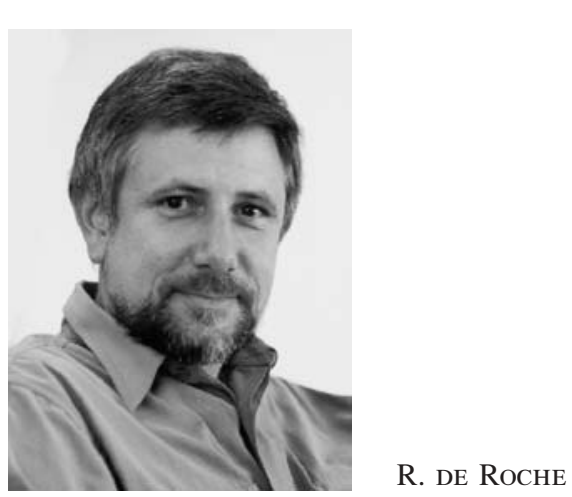

